\section{D PRINTED BELT WHEELS FOR USE IN DESIGN OF BICYCLES}

PATRIK SNIEHOTTA

VSB-TUO, 17. listopadu 15/2172, 70800 Ostrava - Poruba, Czech Republic

DOI : 10.17973/MMSJ.2020_03_2019128

patrik.sniehotta@vsb.cz

The article describes how it is possible to use 3D printing for printing belt wheels for bicycles. New categories of bikes keep appearing in the market. For the use, specially cities that are bikes, that use belt instead of a traditional chain. With new generations of belts, this power transmission can be used on mountain bikes. But a belt-driven bike must have a special frame, because the belt cannot be disconnected like a classic chain. Even with modern 3D CAD applications a company needs to make a prototype and check their design. That is not only important for the function of the bicycle, but also to prove the assembly or maintenance processes. In comparison with a chain, the belt-driven system is more expensive. For small companies, it is then difficult to buy different gearing combinations, just for checking the design. In this case, the 3D printing comes in handy, because it can produce very quickly cheap belt wheels with different tooth combinations or design of the belt wheel. With more advanced methods (like the selective laser sintering) of 3D printing, it is possible to produce even functional belt wheels that have the same ore even better properties compared to traditional injection molding. This article shows the possibilities in the prototyping of belt wheels with different 3D printing methods.

Keywords:

Cost, 3D Printing, Belt drive

\section{INTRODUCTION}

When it comes to drivetrain, the common choice for a bicycle manufacturer is the chain. It is a proven concept and almost every year it becomes more reliable and lighter. Today you can see bicycles with triple chainrings at the front and 8 gears in the back on the cheapest bikes, up to the one by twelve (and even one by thirteen) systems on the middle of the range bicycles and going up to the top of the range models. However, on every of these bicycles you need to maintain the key element of the system and that is the chain. Normally, that means to clean and lubricate the chain. But when the chain is lubricated, mostly with oil or wax, the cyclist can get dirty from it. For a road or mountain cyclist wearing close-fitting clothing, it is not such a big problem, but for a commuter on his way to work, dirty trousers can be an annoying problem. That's where the belt drive shows its advantages.
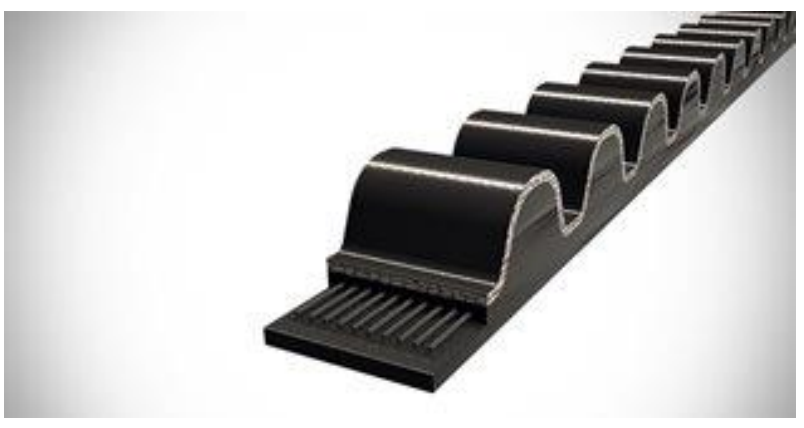

Figure 1. Continental CBD belt. [Continental bicycle systems-1 2018]

Because a belt does not need lubrication, you cannot get dirty from it. And because there is no lubricant, it cannot be washed out when cleaning and you do not have to worry where to clean the bicycle so as not to, for example, contaminate the earth with oil. A belt-driven bicycle can be simply cleaned with a garden hose and water. That is a big advantage for an average person who commutes to work and does not want to spent hours cleaning his bicycle.

On the other hand, there are two major drawbacks connected with the use of the belt. The first is that gear changes you need to have a gear box, because you cannot change belt wheels like on a cassette of a traditional bike. The second problem is not so obvious for the layman, but on a belt-driven bicycle you need a split backend in order to get the belt into the frame. A belt cannot be split in two like a chain. That means that a frame for a belt-driven bicycle is more complicated and therefore a little bit more expensive. Also, the mounting of the back wheel must be designed so, that there can be provided a belt tension. But this is similar to a single speed (without or with a gearbox) chain bicycle.

For a bicycle designer, it is important to check carefully the design of a new bike he is making. For the belt-driven system, the parallelism tolerances, which are in millimeters, are very important. Therefore, the 3D printing is a very helpful method, which can make very fast and cheap prototypes.

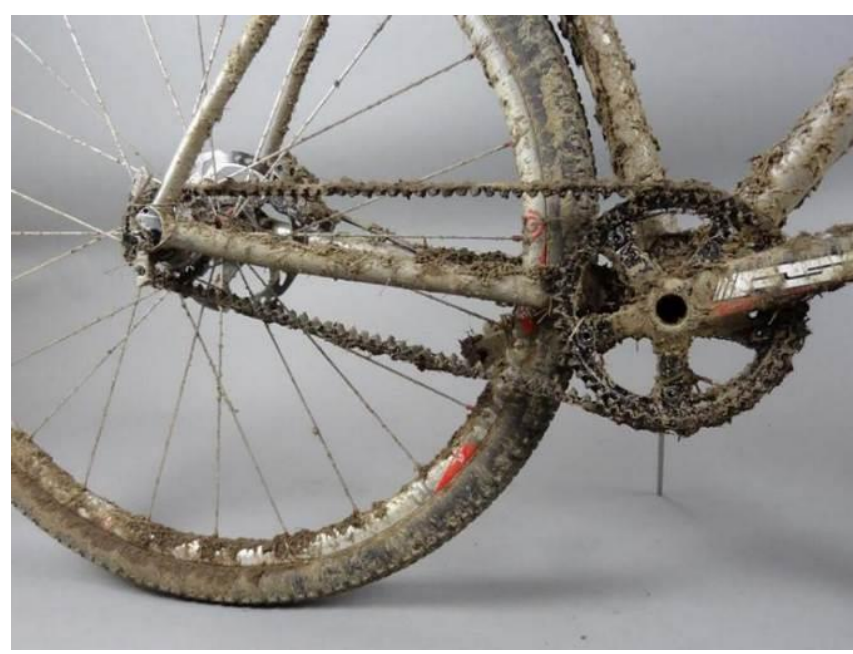

Figure 2. Example of a belt drive dirty by mud. [Naked bicycles 2018]

As the belt wheels need to be accurate collinear, there is a bigger need to make more prototypes of belt wheels. There can be more than one right solutions of this problem and for every tooth combination of belt wheels and wheel offset it would be very expensive to buy an original belt wheel. The 3D printing method can then produce almost every design of the belt 
wheel, but the use of this method has its rules [NovakovaMarcincinova 2011] [Novakova-Marcincinova 2012].

\section{METHODS AND MATERIALS}

When designing a new belt-driven system, the designer has to choose if he wants to use a belt already designed for bicycles and then just designs the number of teeth, belt line and mounting points. He can also choose to design a fully new system with a new type of belt and then he has to design the tooth profile. In both cases (of course in the latter case even more), the 3D printing comes in very handy and accelerates the design process. In our case, we have chosen to optimize the belt wheels for the Continental CDS 1400 belt, which was specially designed for the use on bicycles and is reinforced with carbon fiber. It differs from other belts in the yellow surface of the inner layer of the teeth.

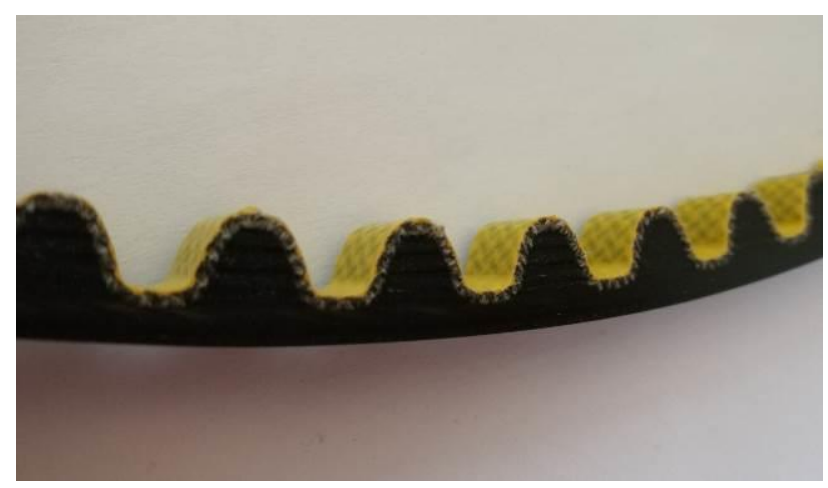

Figure 3. Continental CBD belt 1400

At the beginning, we bought the CBD belt sprocket to see what the shape of the tooth profile is, that we didn't have to invent the profile by ourselves from the scratch. The original $C B D$ sprocket is also completely made out of plastic, which is similar to the sprockets made later using the 3D printing.

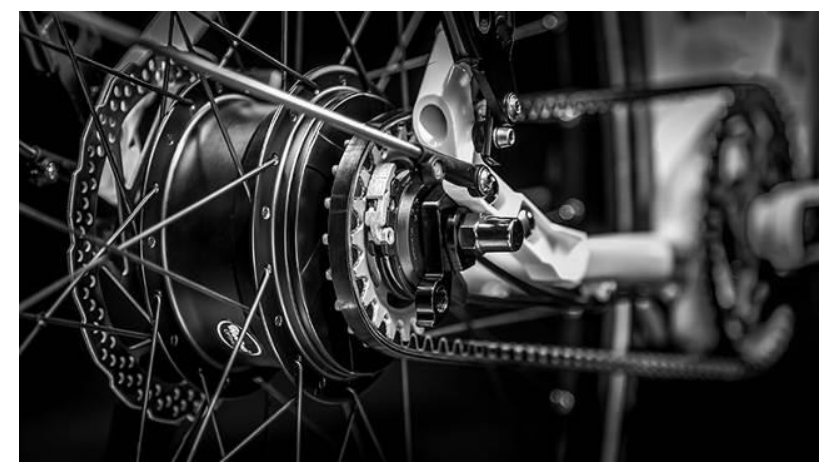

Figure 4. Continental CBD sprocket. [Continental bicycle systems-2 2018]

At the beginning, we measured the original sprocket and the belt and modeled them then in a 3D CAD program. We found out that, for the mechanical design of parts, the Autodesk Inventor program is better, but for "bending" the belt and checking the sprocket-belt touch, the Dassault Systèmes Solidworks is the better solution.

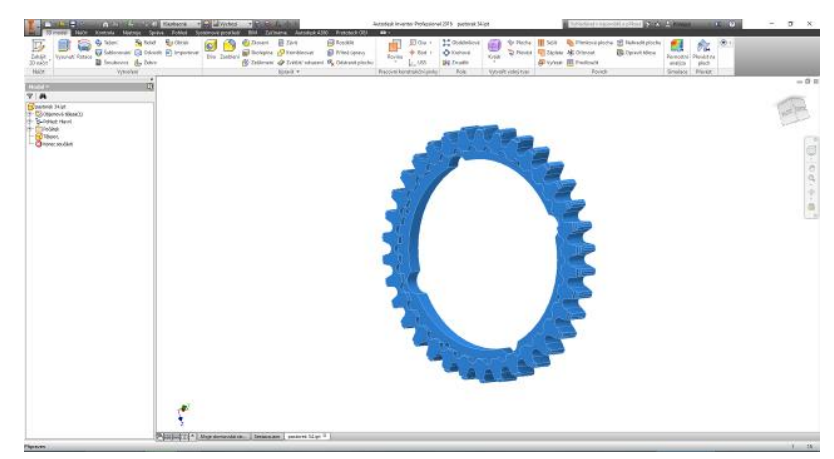

Figure 5. Sprocket designed in Autodesk Inventor.

The critical point of the design is that the pitch between the tooth on the belt and on the sprocket has to be as similar as possible. Even a difference in hundreds of millimeters can cause (especially on the front sprocket) an interference of belt and sprocket.

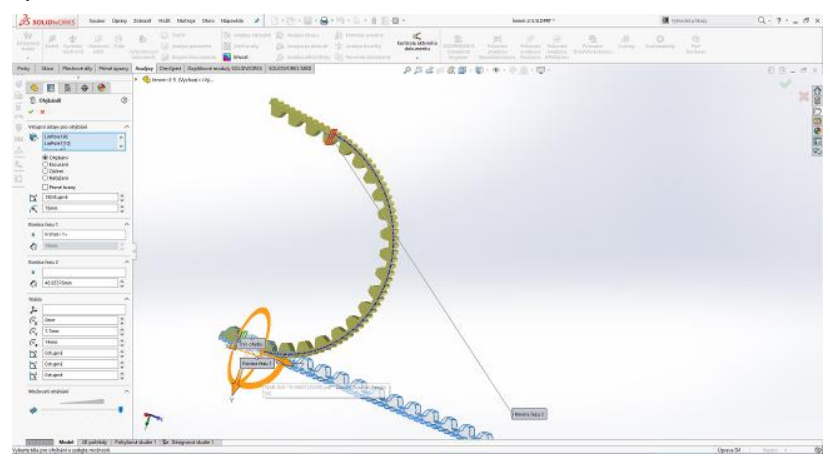

Figure 6. Bended belt model in Solidworks

For testing the printing methods, we have chosen two printers that are normally designed for home use:

\section{- FELIX Pro 2 \\ - PRUSA I3 MK3}

These printers are cheap to purchase and also the printing itself is cheap. This type of printers can use different filaments. We used the PLA (polylactic acid) wire.

For the third printer, we chose a professional Selective Laser Sintering (SLS) printer EOS P 396. The material was polyamide PA2200. This printer makes a much better samples, but its price is diametrically higher than for the "PLA" printers

[Hernandez 2015] [Kaziunas 2013]. Therefore, it was interesting to find out if the more expensive method brings so much advantages, compared to the price.

\section{RESULTS}

We made several sprockets with all three printers. More samples were made with "PLA" printers, due to the low price of the samples. The best quality, as expected, was reached with the SLS printer [Horvath 2014]. 


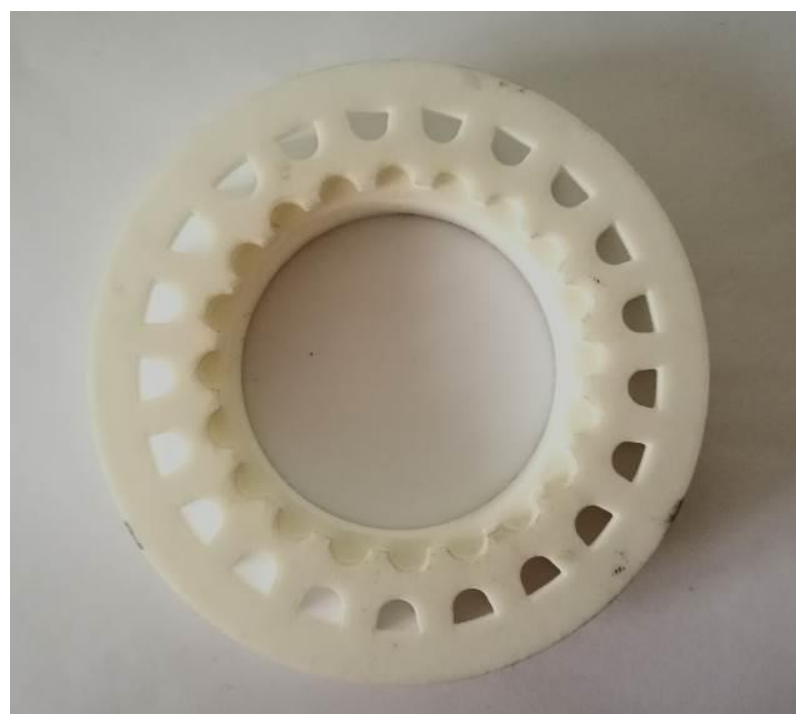

Figure 7. Sprocket made by SLS method

The sprockets made with the SLS printer, due to the used method, were homogeneous, without any cavities. This is useful during the prototyping phase, where it is necessary to make some corrections to the design or make some holes. Also, these samples were the most accurate.

Sprockets made out of PLA were not so accurate as with SLS (but there were examples that were very near), but the resulting accuracy was fine considering the purpose. The problem with this method was the setting of the wire trajectory.

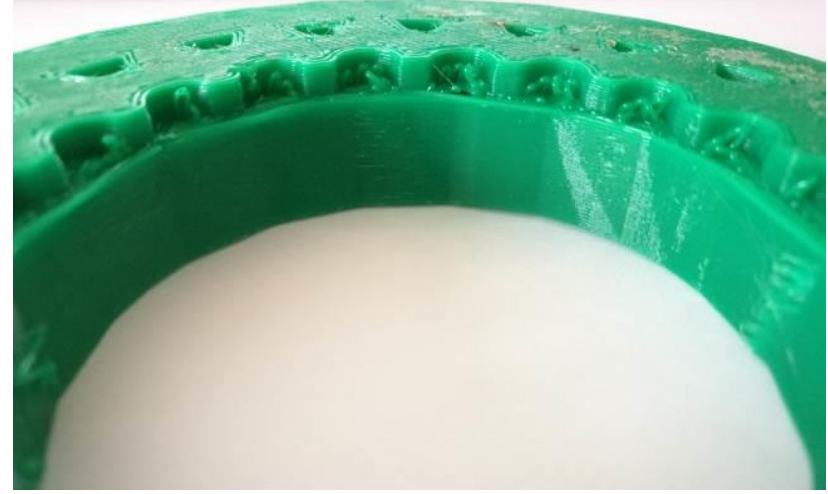

Figure 8. Example of bad printing

By this method lays the printing head track by track. To shorten the time and reduce the costs, the printer makes at the beginning a contour of each layer and then fills the inner space. The designer can choose how much tracks the printer should make - how thick would be the contour. The filling does not have to be filled by $100 \%$. The printer can for example fill the space just by $30 \%$ and the rest are "cavities". This possibility for the designer to choose these parameters can dramatically affect the end result of the printing [Horvath 2014].

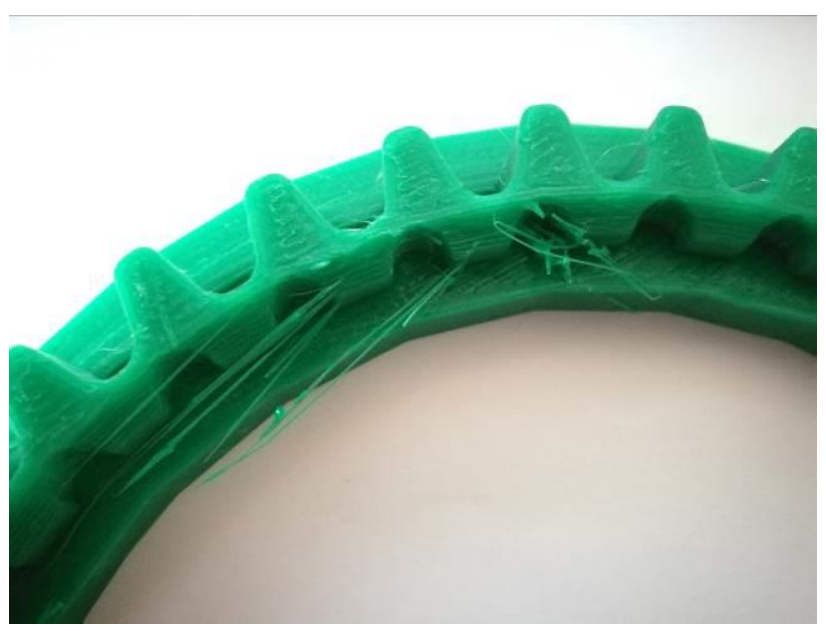

Figure 9. Example of bad printing

There are of course limits of this method that cannot be compensated even by good setting of the printing trajectory. The first problem is that the printer that uses a wire (PLA, ABS, ...) makes thicker layers than the SLS printer. That means that the resulting roughness of the surface is greater than with the SLS method. For the belt sprockets, this is an issue also when each layer is a little bit offset to the previous one. Then during the use, the tooth surface is smoothened and this results in a bigger clearance between the belt and the tooth. This bigger clearance led to a bigger noise and axial movement of the belt on the sprockets.

The second problem, depending on the filling method, is that the final parts cannot be so easily machined. Also, the printing method itself makes the machining more difficult than by the SLS method. The printing wire has a round profile and when the paths are between each other, there are always small gaps between each path. That makes, for example, the drilling of small holes difficult, because the material is then not homogeneous, and the machining resistance is then not constant.

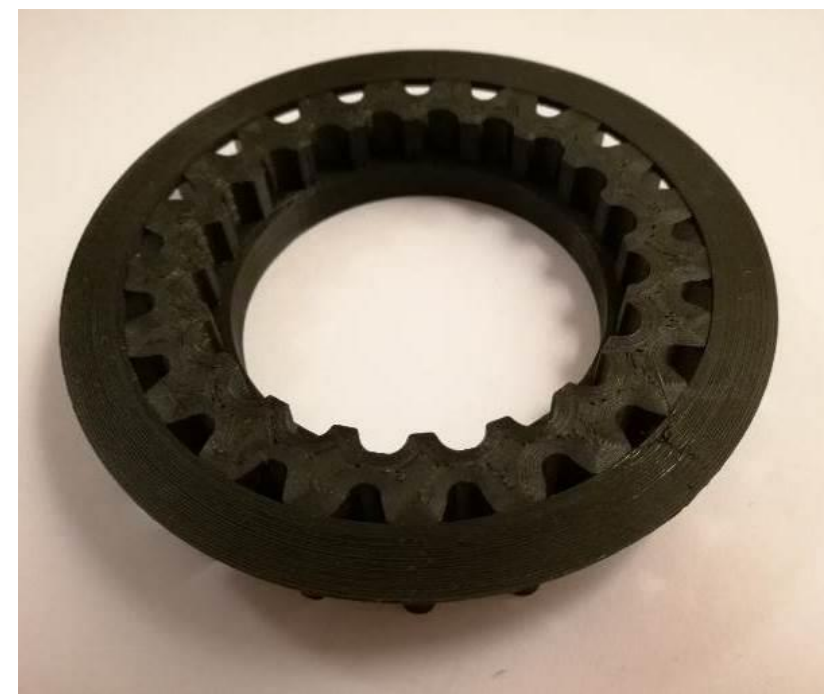

Figure 10. Example of good printed sprocket, made out of two parts 


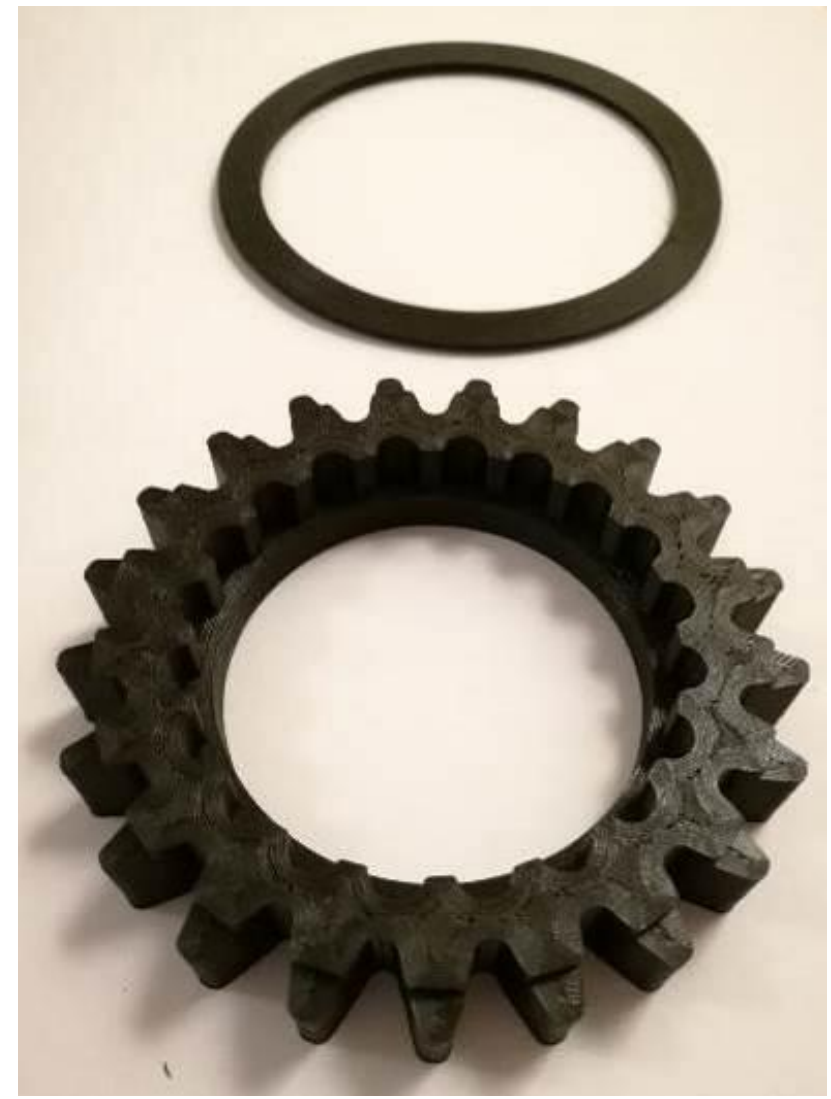

Figure 11. Example of two-part sprocket separated into parts

The third problem is that when the parts are too complex, e.g. when there is a guide flange on the sprocket, the part must be split into several parts. Then the parts must be glued together. That requires an additional time and the gluing brings an inaccuracy into the final part. 


\section{CONCLUSIONS}

Like in other industry areas, the 3D printing can speed up the design process in the early, but also in the later stages of the development. The SLS method can be used not only in the prototyping stages, but also in the regular production. The quality can be compared to plastic parts made by injection molding. The quality and strength of the sprocket is the same as or better than the molded parts. The price of these two methods is almost the same.

At the first sight, it seems that the PLA printers have a lot of disadvantages. On the other hand, with a good preparation process, the accuracy of final parts can almost be the same as with the SLS printers. The strength of the part would be not so high, but the loads on the belt-driven sprocket are so low, that this lower strength is not a problem. The biggest advantage is the price of the final part. For the belt-driven sprockets, the PLA method is almost 8times cheaper than the SLS or injection molding method.

\section{ACKNOWLEDGMENTS}

This study was supported by SP2020/02 project.

\section{REFERENCES}

[Beniak 2014] Beniak, J., Križan, P., Matúš, M., Svatek, M., Ecological PLA plastic used for FDM rapid prototyping technology, 15th International Multidisciplinary Scientific Geoconference and EXPO, SGEM 2015; Albena; Bulgaria; 18 June 2015 through 24 June 2015, Volume 1, Issue 2, 2015, Pages 117-123, DOI: 10.5593/SGEM2015/B21/S7.016 [Continental bicycle systems-1 2018] Continental bicycle systems. CBD-Belt, location [online]. 10.5.2018/10.5.2018 [13.6.2018]. Available from http://www.continental-bicyclesystems.com/en-gl/eBikes/Belt-Drive/CBD-Belt. [Continental bicycle systems-2 2018] Continental bicycle systems. Technical advices, location [online].

10.5.2018/10.5.2018 [13.6.2018]. Available from http://www.continental-bicycle-systems.com/engl/Ebikes/Belt-Drive/Technical-advice

[Hernandez 2015] Hernandez, D. D. Factors Affecting Dimensional Precision of Consumer 3D Printing. International Journal of Aviation, Aeronautics, and Aerospace, September 2015, Vol.2, No.2., pp 1-43, ISSN (if applicable) [Horvath 2014] Horvath J. Mastering 3D Printing, 1st edn., O'Reilly and Associates, Berlin, 2014. ISBN: 978-1-4842-0026-1 [Kaziunas 2013] Kaziunas, A. Make: 3D Printing: The Essential Guide to 3D Printers. 1st edn, O'Reilly and Associates, Sebastopol, 2013. ISBN: 1457182939

\section{CONTACTS}

Ing. Patrik Sniehotta, Ph.D.

VSB-TUO, Department of Machine Parts and Mechanisms 17. listopadu 15/2172, 70800 Ostrava - Poruba, Czech Republic +420 597324 313, patrik.sniehotta@vsb.cz,www.vsb.cz
[Naked bicycles 2018] Naked bicycles. Titanium Belt Drive X Fighter, location [online]. 26.11.201/26.11.2014 [13.6.2018]. Available from https://nakedbicycles.com/gallery/titaniumbelt-drive-x-fighter/2014/11/26.

[Novakova-Marcincinova 2011] T Novakova-Marcincinova, L., Fecova, V., Novak-Marcincin, J., Janak, M., Barna J. In-telligent design of experimental gearbox with Rapid Prototyping technology support. In: 15th IEEE International Conference on Intelligent Engineering Systems, Poprad, Slovakia pp. 77-80. ISSN: 1543-9259

[Novakova-Marcincinova 2012] Novakova-Marcincinova, L., Fecova, V., Novak-Marcincin, J., Janak, M., Barna J. Ef-fective utilization of rapid prototyping technology, 2012, Vol.57, No.1431., 834-841 